\title{
Involving Men Volunteers to Effectively Respond to the Problem of Gender- based Violence in Myanmar: United Nations Population Fund
}

\author{
Saurabh Ram Bihari Lal Shrivastava* and Prateek Saurabh Shrivastava
}

Department of Community Medicine, Shri Sathya Sai Medical College and Research Institute, Kancheepuram, India

\begin{abstract}
Gender-based violence has been regarded as one of the major social public health concerns affecting women from all walks of life across the world. Moreover, the incidence of the problem increases enormously in regions which are facing humanitarian emergencies. In order to respond to the problem of violence against women living in a displacement camp in Myanmar, the United Nations Population Fund started a new initiative to develop a network of male volunteers to prevent violence and adequately respond to assist the victims. To conclude, the problem of gender based violence cannot be eliminated unless men are actively involved in the drive. The current strategy of developing a network of men and involving them to counter this menace is quite an effective approach and the program managers from different parts of the world should aim to take a leaf out of it and replicate the same in their settings for a better and a favorable outcome.
\end{abstract}

Keywords: Gender-based violence; Men; Myanmar

\section{INTRODUCTION}

Gender-based violence has been regarded as one of the major social public health concerns affecting women from all walks of life across the world [1]. In-fact, the global estimates indicate that almost $35 \%$ of the women are being subjected to some form of physical or sexual violence, which is an alarming figure and clearly suggest that their human rights violations have become a norm and is not a rare occurrence [2]. Furthermore, in most of the communities, it is regarded as a private issue and thus very rarely reported due to the associated stigma $[1,2]$.

\section{Distribution and determinants of gender-based violence}

The gender-based violence is more of a social concern as the same trend has continued for generations together, where women have been considered inferior to men [1]. Further, almost all grown-up men and women have witnessed the incidents of violence in their past, while they were kids, owing to which every segment of the society believe it to be a part of the lives of women, where men can abuse women, while women are expected to live with the same without thinking that it is something against which they have to raise their voice or seek appropriate attention [1,2]. Moreover, the incidence of the problem increases enormously in regions which are facing humanitarian emergencies [3-5].

\section{Prevention and control of gender-based violence in Myanmar}

Acknowledging the deep roots of the problem in the human society, the impact which it results in the growth and development of a woman, and eventually the progress of a nation, efforts have been taken to neutralize this divide between men $\&$ women [1,5-7]. In order to respond to the problem of violence against women living in a displacement camp in Myanmar, the United Nations Population Fund started a new initiative to prevent violence and adequately respond to assist the victims [8]. This initiative has two main aspects, namely developing a network of male volunteers to create awareness about the indispensable need to end violence, and to extend medical care, psychosocial support \& legal aid to the survivors of violence [8].

The primary objective of the initiative was to reach out to other men, not only to sensitize them about the ill-effects associated with gender-based violence, but even to intervene and discourage men who indulge in domestic violence by counseling them as

Correspondence to: Dr. Saurabh Ram Bihari Lal Shrivastava, Department of Community Medicine, Shri Sathya Sai Medical College and Research Institute, Kancheepuram, India, Tel: 919884227224; E-mail: drshrishri2008@gmail.com

Received: December 18, 2018, Accepted: January 18, 2019, Published: January 24, 2019

Citation: Shrivastava SRB, Shrivastava PS (2019) Involving Men Volunteers to Effectively Respond to the Problem of Gender-Based Violence in Myanmar: United Nations Population Fund. Biol Med (Aligarh) 11:453. doi:10.35248/0974-8369.19.11.453.

Copyright: (C) 2019 Shrivastava SRB, et al. This is an open-access article distributed under the terms of the Creative Commons Attribution License, which permits unrestricted use, distribution, and reproduction in any medium, provided the original author and source are credited. 
well as by involving local community leaders $[8,9]$. The initiative has started to show encouraging results, as the incidence of gender-based violence has remarkably declined, and is clearly evident that husbands, fathers, brothers and sons all have started to attend the sensitization sessions, and is even providing a platform for them to discuss their other issues [8].

Moreover, this gives an opportunity for men volunteer to work with female staffs in collaboration and expand the reach of their services [8]. However, before enrolling them as volunteers, men are screened before their recruitment to ensure that they are not themselves the perpetrators [8]. The current strategy of developing a network of men and involving them to counter this menace is quite an effective approach as evidenced in the studies done in Dar es Salaam and other settings [10-13].

\section{CONCLUSION}

To conclude, the problem of gender based violence cannot be eliminated unless men are actively involved in the drive. The program managers from different parts of the world should aim to take a leaf out of it and replicate the same in their settings for a better and a favorable outcome.

\section{REFERENCES}

1. Shrivastava SR, Shrivastava PS, Ramasamy J. Working together to accomplish gender equality in health: World Health Organization. Annals of Tropical Medicine and Public Health. 2016;9(4): 286-287.

2. Violence against women - Fact sheet. World Health Organization. 2017.

3. Shrivastava SR, Shrivastava PS, Ramasamy J. Implementing universal minimal standards to counter the challenge of genderbased violence in emergencies. Annals of Tropical Medicine and Public Health. 2016;9(4):289-290.

4. Jewkes R, Jama-Shai N, Sikweyiya Y. Enduring impact of conflict on mental health and gender-based violence perpetration in
Bougainville, Papua New Guinea: A cross-sectional study. PLoS One. 2017;12(10):e0186062.

5. Mootz JJ, Stabb SD, Mollen D. Gender-based violence and armed conflict: A community-informed socioecological conceptual model from northeastern Uganda. Psychol Women Q. 2017;41(3): 368-388.

6. Wirtz AL, Perrin NA, Desgroppes A, Phipps V, Abdi AA, Ross B, et al. Lifetime prevalence, correlates and health consequences of gender-based violence victimisation and perpetration among men and women in Somalia. BMJ Global Health. 2018;3(4):e000773.

7. Muche AA, Adekunle AO, Arowojolu AO. Gender-based violence among married women in Debre Tabor town, northwest Ethiopia: A qualitative study. Afr J Reprod Health. 2017;21(4):102-109.

8. Not just a women's issue: Men in Myanmar take on gender-based violence. United Nations Population Fund. 2016.

9. Sommanustweechai A, Putthasri W, Nwe ML, Aung ST, Theint MM, Tangcharoensathien V, et al. Community health worker in hard-to-reach rural areas of Myanmar: filling primary health care service gaps. Human Resource Health. 2016;14(1):64.

10. Casey EA, Leek C, Tolman RM, Allen CT, Carlson JM. Getting men in the room: perceptions of effective strategies to initiate men's involvement in gender-based violence prevention in a global sample. Cult Health Sex. 2017;19(9):979-995.

11. Maman S, Kajula L, Balvanz P, Kilonzo M, Mulawa M, Yamanis T. Leveraging strong social ties among young men in Dar es Salaam: A pilot intervention of microfinance and peer leadership for HIV and gender-based violence prevention. Global Public Health. 2016;11(10):1202-1215.

12. Casey E, Carlson J, Two Bulls S, Yager A. Gender transformative approaches to engaging men in gender-based violence prevention: A review and conceptual model. Trauma Violence Abuse. 2018;19(2):231-246.

13. Storer HL, Casey EA, Carlson J, Edleson JL, Tolman RM. Primary prevention is? A global perspective on how organizations engaging men in preventing gender-based violence conceptualize and operationalize their work. Violence Against Women. 2016;22(2): 249-268. 